\title{
O SUJEITO ADOLESCENTE E O CORPO: UMA LEITURA PSICANALÍTICA
}

\section{The Adolescent Subject and the Body: A Psychoanalytic Reading}

\author{
El Sujeto Adolescente y el Cuerpo: Una Lectura Psicoanalítica
}

\section{Le Sujet Adolescent et le Corps : Une Lecture Psychanalytique}

10.5020/23590777.rs.v20iEsp2.e9311

\section{Pollyana Silveira de Almeida 9}

Psicanalista. Especialista em Teoria da Clínica Psicanalítica (UFBA). Mestre em Psicologia (UFBA). Membro do Fórum Salvador (Escola de Psicanálise dos Fóruns do Campo Lacaniano - Brasil).

\section{Andréa Hortélio Fernandes 9}

Psicanalista, Doutora em Psicopatologia Fundamental e Psicanálise (Paris 7), Pós-doutorado no Programa de Pós-graduação em Psicologia (UFS), Membro do GT: Psicanálise, Clínica e Política da ANPEPP, Analista Membro da EPFCL, Membro do Fórum Salvador (EPFCL-Brasil).

\section{Resumo}

A questão da infância e do que resta de infantil na estrutura do sujeito está posta desde Freud e é partilhada por diversos autores até hoje. E quanto ao "sujeito adolescente"? O que se pode dizer sobre a sua relação com o inconsciente? Entende-se que o termo "sujeito adolescente", embora não tenha sido utilizado pelos cânones, está em consonância com o ensino de Freud e de Lacan sobre o inconsciente estruturado como uma linguagem. Enquanto o indivíduo adolescente (púbere) indica uma pessoa que se encontra em uma determinada faixa etária (não unânime), na qual são esperadas transformações biológicas, o sujeito adolescente indica o efeito, a resposta aos impasses da vida humana que se manifestam através das formações do inconsciente. No entanto não há como não se deparar com a questão das transformações pubertárias em um determinado momento da vida. Propõe-se que a adolescência ex-siste à puberdade, no sentido de ter com ela pontos de convergência, mas, ao mesmo tempo, ser não-toda circunscrita pelas transformações anatomofisiológicas. Diante disso, algumas questões tornam-se pertinentes, especialmente após mais de um século da publicação dos Três Ensaios de Freud, em que o autor fala da puberdade a partir dos marcadores biológicos, mas também para além deles, evidenciando as exigências do trabalho de subjetivação, que se impõem com as transformações corporais. Dessa maneira, este trabalho parte das seguintes questões: como articular essa passagem temporal diacrônica que promove maturação biológica à temporalidade lógica da adolescência? O que é o corpo adolescente? E o que dizer do encontro com o corpo do Outro?

Palavras-chave: adolescência; corpo; sujeito; Outro.

\section{Abstract}

The question of childhood and what remains of children in the structure of the subject has been raised since Freud and is shared by several authors until today. What about the "teenage guy"? What can you say about its relationship with the unconscious? It is understood that the term "adolescent subject", although not used by the canons, is in line with the teaching of Freud and Lacan on the unconscious structured like a language. While the adolescent (pubescent) individual indicates a person who is in a certain age group (not unanimous), in which biological transformations are expected, the adolescent subject indicates the effect, the response to the impasses of human life that are manifested through training unconscious. However, there is no way not to face the issue of pubertal changes at a certain time in life. It is proposed that adolescence extends to puberty, in the sense of having points of convergence with it, but, at the same time, not being entirely circumscribed by anatomy physiological transformations. Because of this, some questions become pertinent, especially after more than a century of the publication of Freud's Three Essays, in which the author speaks of puberty based on biological markers, but also 
beyond them, highlighting the demands of subjectivation work, which impose themselves with bodily transformations. Thus, this work starts with the following questions: how to articulate this diachronic temporal passage that promotes biological maturation to the logical temporality of adolescence? What is the teenage body? And what about the encounter with the Other's body?

Keywords: adolescence; body; subject; Other.

\section{Resumen}

La cuestión de la niñez y de lo que queda de infantil en la estructura del sujeto está puesta desde Freud y es compartida por muchos autores hasta hoy. ¿Y cuanto al "sujeto adolescente”? ¿Qué se puede decir sobre su relación con el inconsciente? Se entiende que el término "sujeto adolescente", aunque no haya sido utilizado por los cánones, está de acuerdo con la enseñanza de Freud y Lacan sobre el inconsciente estructurado como un lenguaje. Mientras el individuo adolescente (púbere) indica una persona que se encuentra en un determinado grupo etario (unánime), en la cual se esperan transformaciones biológicas, el sujeto adolescente indica el efecto, la respuesta a los problemas de la vida humana que se manifiestan por medio de las formaciones del inconsciente. Sin embargo, no hay cómo no encontrarse con la cuestión de las transformaciones de la pubertad en un determinado momento de la vida. Se propone que la adolescencia "ex-siste" a la pubertad, en el sentido de tener puntos de convergencia con ella, pero, al mismo tiempo, no ser totalmente circunscrita por las transformaciones anátomo-fisiológicas. Ante esto, algunas cuestiones se ponen pertinentes, especialmente después de más de un siglo de la publicación de los Tres Ensayos de Freud, en que el autor habla de la pubertad a partir de los marcadores biológicos, pero también para allá de ellos, evidenciando las exigencias del trabajo de subjetivación, que se imponen con las transformaciones corporales. De esta forma, este trabajo parte de las siguientes cuestiones: ¿Cómo articular este paso temporal diacrónico que promueve maturación biológica a la temporalidad lógica de la adolescencia? ¿Qué es el cuerpo adolescente? ¿Qué decir del encuentro con el cuerpo del Otro?

Palabras clave: adolescencia; cuerpo; sujeto; Otro.

\section{Résumé}

La question de l'enfance et de ce qui reste des enfants dans la structure du sujet est posée depuis Freud et est partagée par plusieurs auteurs jusqu'à aujourd'hui. Et le « sujet adolescent »? Que peut-on dire de leur relation avec l'inconscient ? Le terme « sujet adolescent », bien qu'il n'ait pas été utilisé par les canons, a suivi l'enseignement de Freud et de Lacan sur l'inconscient structuré en langage. L'individu adolescent (pubescent) désigne une personne appartenant à un certain groupe d'âge (non unanime), dans lequel certaines transformations biologiques sont attendues. Le sujet adolescent, à son fois, indique l'effet, la réponse aux impasses de la vie humaine qui se manifestent à travers les formations de l'inconscient. Cependant, il n'y a aucun moyen de ne pas faire face à des changements pubertaires à un certain moment de la vie. On propose que l'adolescence s'étende à la puberté, dans le sens d'avoir des points de convergence avec elle, mais, en même temps, ne pas être entièrement circonscrite par des transformations anatomophysiologiques. Devant cela, certaines questions deviennent pertinentes, surtout après plus d'un siècle de publication des "Trois essais» de Freud, dans lequel l'auteur parle de la puberté à partir de marqueurs biologiques, mais aussi au-delà de ces marqueurs, en mettant en évidence les exigences de subjectivation, dans lesquelles sont imposées avec des transformations corporelles. Désormais, ce travail part des questions suivantes : comment articuler ce passage temporel diachronique qui favorise la maturation biologique à la temporalité logique de l'adolescence? Qu'est-ce que le corps de l'adolescent? Et quoi dire sur la rencontre avec le corps de l'Autre?

Mots-clés : adolescence ; corps ; matière ; Autre.

Podemos considerar a adolescência como um fenômeno humano complexo e plural de concepções, a depender do momento histórico e do contexto cultural, ou mesmo socioeconômico, uma vez que é questionável se o que se chama adolescência é permeado dos mesmos significantes entre as classes sociais. Apesar de diversos autores estarem atentos a essa multiplicidade conceitual, o que se percebe é que ainda circula um discurso que naturaliza a adolescência como vivência universal, a despeito das mudanças históricas, culturais, sociais e, acrescentamos agora, singulares. Conforme SchoenFerreira, Aznar-Farias, \& Silvares, 2010, p. 228), "a adolescência, hoje, não é mais encarada apenas como uma preparação para a vida adulta, mas passou a adquirir sentido em si mesma", cabendo, entretanto, questionar esse sentido, uma vez que os modos de subjetivação dos sujeitos revelam, de algum modo, os discursos de uma época. Lacan, seguindo a trilha de Freud, que não se furtou a pensar a cultura do seu tempo, diz: 
Que antes renuncie a isso [à psicanálise], portanto, quem não conseguir alcançar em seu horizonte a subjetividade de sua época. Pois, como poderia fazer de seu ser o eixo de tantas vidas, quem nada soubesse da dialética que o compromete com essas vidas num movimento simbólico. Que ele conheça bem a espiral a que o arrasta sua época na obra contínua de Babel, e que conheça sua função de intérprete na discórdia das línguas. (Lacan, 1998a, p. 322)

A contemporaneidade, após a dupla virada de século e milênio, é marcada pelo advento da internet e pelo avanço das tecnologias digitais, como o aparecimento e expansão das chamadas redes sociais, em que proliferam as selfies. Embora transformações importantes tenham ocorrido em diversos campos, não há como negar que o estabelecimento de um mundo online tenha instaurado uma nova discursividade, de maneira a influenciar os laços sociais, as relações de poder e os modos de subjetivação.

Se a individualidade é a categoria fundamental que define o ideário da modernidade (Birman, 2006), a sociedade ocidental pós-moderna tem como traço fundamental a estetização de si, "ou seja, uma plena e extensa consciência, decididamente focada ao tratamento de si como uma mercadoria" (Kyrillos \& Dunker, 2004, p. 58). Essa ideia do indivíduo como empreendedor de si mesmo está intimamente ligada ao advento do capitalismo, que transformou o mundo, modificou radicalmente e "continua a modificar os meios de produção (...), subverte a economia biológica do planeta e, mais importante, modifica as subjetividades" (Soler, 2018, p. 27). No que tange à adolescência, enquanto produção discursiva no mundo capitalista, ela se torna um tempo de indeterminação em que todas as escolhas "ainda estão pendentes enquanto o organismo completou sua maturação" (Soler, 2017, p. 36).

Ao longo dos anos, tornou-se perceptível que a adolescência é um produto da subjetividade produzida pelo capitalismo. Historicamente, os adolescentes tendem a constituir agrupamentos na tentativa de pleitear uma identidade de grupo, por meio da construção de hábitos comuns de conduta e de consumo. Assim posto, para além dos laços entre eles, o que os une é o laço de cada adolescente com um objeto passível de responder pelo pertencimento ao grupo. Encontramos, em tal modo de funcionamento, a base daquilo que Jacques Lacan protagonizou ao propor o discurso capitalista. Em algum momento da história, houve uma transformação no discurso do mestre e, a partir do que Lacan chamou de "mutação capital", houve um esvaziamento da impotência do mestre. Como diz, "por terem sido dissipadas as nuvens da impotência" (Lacan, 1992, p. 189), o discurso capitalista faz crer que tudo pode, que é possível fazer existir a relação sexual dada a relação direta entre o \$ e o objeto (a) nesse discurso $\left(\$ / \mathrm{S}_{1}{ }^{\circledR a} \mathrm{a} / \mathrm{S}_{2}\right)$, numa tentativa sempre fracassada de uma completude fantasmática.

Assim, a característica fundamental que este tempo histórico marcado pelo discurso do capital apresenta aos jovens é, segundo Soler (2017), a do tempo do suspense, o qual implica, necessariamente, as expectativas ainda não sujeitas a qualquer teste de realidade, grandes sonhos e até potencialidades utópicas. Diz a autora que este tempo é tão determinado pelo discurso capitalista que conhecemos sociedades nas quais a adolescência, enquanto discursividade, não existe. Dessa maneira, os impasses dos sujeitos adolescentes em responder pelo desejo e o gozo os levam a hesitar na operação de desalienação dos ideais sociais aos quais estão apalavrados, por neles se alojarem.

A psicanálise lacaniana, ao partir da hipótese de que o inconsciente é estruturado como uma linguagem, leva em consideração que a economia capitalista instaura uma ordem discursiva que se infiltra nos indivíduos que estão dentro dessa economia. Os estudos de Freud (1921/1996g, 1923/1996h) sobre a psicologia das massas e sobre a segunda tópica do aparelho psíquico enfatizaram que o indivíduo e o social são solidários ao discurso do seu tempo.

No que tange aos sujeitos adolescentes, há uma travessia a ser feita no nível das identificações. As primeiras identificações, com as autoridades familiares e sociais, circunscrevem sujeitos apalavrados a um discurso, ao qual eles se alojam e com os quais se configuram modalidades de gozo. É nesse sentido, também, que é possível articular a adolescência como uma forma de subjetividade produzida pelo capitalismo. Os sujeitos adolescentes, ao promoverem a queda das primeiras identificações, constroem outros ideais, outros ídolos, que, mesmo pela negativa, terminam por reproduzir os discursos aos quais eles tornaram-se apalavrados.

Contudo, pelo fato de ser franqueada aos sujeitos adolescentes a possibilidade de vivenciar a sexualidade, o engodo da tentativa de completude fastamática fracassa e leva à subjetivação da falta no Outro. A sexualidade em causa desmonta a possibilidade de soldagem entre o sujeito e seus objetos, pois estes são, desde sempre, metonímicos. A não completude relança a condição de sujeito desejante e intérprete para além dos marcadores biológicos.

Nesse cenário, o mal-estar, que é constitutivo do ser humano, apresenta-se em modos de sofrimento, cujos novos enunciados remetem a uma aliança entre o discurso capitalista e o determinismo biológico, desembocando em uma psiquiatrização da vida. Na clínica, percebe-se a reprodução de ditos como: "Eu sou portador de TDAH"; "Vi no Google que isso que ela tem é bipolaridade"; "Descobri que o problema é TOC", e inúmeras outras categorias sobre as quais não há muita reflexão crítica. Assim, o sujeito, solidário com o discurso do seu tempo, ajusta-se às exigências do laço social, e as disposições psicológicas são tratadas como meios mercantis (Soler, 2018). Esse discurso do capital, em parceria com certo discurso da ciência, favorece a fabricação de pacotes diagnósticos cada vez mais centrados em sintomas e menos em 
quadros clínicos, o que está intimamente ligado à disponibilização de medicações específicas para cada queixa do sujeito, tornada agora uma patologia.

A esse respeito, Moreira e Coutinho (2018, p. 61) mostram que a cultura contemporânea "vem promovendo a fixação de questões e impasses presentificados na adolescência a diagnósticos e a outras nomeações patologizantes/marginalizantes, que esvaziam o lugar de fala do sujeito", não favorecendo que cada um possa tratar seu próprio mal-estar de maneira singular. Além disso, as autoras acreditam que a medicalização também esvazia "a responsabilidade dos diversos atores sociais (escola, família, comunidade etc.) como importantes interlocutores na construção desse discurso próprio pelo adolescente" (Moreira \& Coutinho, 2018, p. 61).

Dada a conjuntura atual, cabe localizar o posicionamento da psicanálise nesse campo de diálogo do que seria a adolescência. No âmbito de um discurso que entendemos como o da psicanálise, trabalhamos, neste artigo, com a hipótese de que a adolescência ex-siste ${ }^{l}$ à puberdade, no sentido de ter com ela pontos de convergência, mas, ao mesmo tempo, ser nãotoda circunscrita pelas transformações anatomofisiológicas. Diante disso, algumas questões tornam-se pertinentes, especialmente após mais de um século da publicação dos Três ensaios sobre a teoria da sexualidade de Freud (1905/1996d), no qual o autor fala da puberdade a partir dos marcadores biológicos, mas também para além deles, evidenciando as exigências de trabalho de subjetivação que se impõem com as transformações corporais.

Desse modo, o presente texto parte de alguns questionamentos que advêm da clínica com sujeitos adolescentes, em especial sobre questões que tangenciam o corpo: como articular essa passagem temporal diacrônica que promove maturação biológica à temporalidade lógica da adolescência? O que é o corpo adolescente? E o que dizer do encontro com o corpo do Outro?

Os procedimentos da pesquisa foram estabelecidos numa estreita articulação entre a clínica e a teoria psicanalíticas. Freud (1912/1996e) já havia declarado que pesquisa e tratamento coincidem na execução da psicanálise, na medida em que os casos interrogam a teoria. As reflexões propostas neste texto surgiram, inicialmente, a partir da realização da pesquisa de mestrado de Almeida (2019), intitulada Trançar e tecer a feminilidade na adolescência: A construção do caso clínico em psicanálise, defendida no Programa de Pós-Graduação em Psicologia da Universidade Federal da Bahia.

A partir dos casos construídos na pesquisa de mestrado, uma nova questão se apresentou e movimentou a escrita deste texto, cuja hipótese central diz respeito à concepção da adolescência enquanto uma produção discursiva instaurada com o capitalismo. Tal perspectiva buscou examinar em que medida o fato de os sujeitos estarem sempre apalavrados ao discurso de sua época contribuiu para o aparecimento de uma forma de subjetividade dita adolescente, que se apresenta para além da puberdade, como marco biológico.

Pelo exposto acima, as autoras foram levadas a construir um artigo teórico-clínico no qual buscaram realizar uma análise crítica de um tema abrangente de investigação, acerca do corpo do sujeito adolescente numa leitura psicanalítica, assunto de grande importância e interesse para as áreas de psicologia, psicanálise, educação e saúde.

Inicialmente, no tópico denominado "Adolescência: como abordar?" será realizada a apresentação do estado da arte do tema, numa interlocução de como a adolescência é permeada pelas mudanças morfológicas da puberdade, ao mesmo tempo em que toda uma nova organização da subjetividade se coloca em funcionamento. A partir da premissa formulada por Freud (1905/1996d), de que a tarefa mais importante a ser realizada pelos adolescentes é o desligamento da autoridade parental que impulsiona uma nova organização subjetiva, duas questões nortearam as elaborações construídas nesta parte do texto: o que podemos dizer da relação do sujeito adolescente com o inconsciente? E como o sujeito adolescente lida com a diferença sexual?

Para tanto, é apresentada e fundamentada a definição da expressão "sujeito adolescente" (Alberti, 2009) em conexão com o fato de a psicanálise considerar o sujeito como efeito do significante e dele se presentificar nas formações do inconsciente, que são produções da linguagem, especificidade do humano, para além da fisiologia molecular de todo corpo vivo.

A adolescência, ao ser entendida pela psicanálise como uma forma de subjetividade resultante do capitalismo, convoca que a clínica psicanalítica leve em consideração os tempos de efetuação da estruturação psíquica e tente dar voz aos sujeitos adolescentes. Dessa forma, o discurso do psicanalista assume a tarefa de acolher a subjetividade de cada época, abrindo espaço para as elucubrações de saber própria a cada um em particular, o que pode franquear aos sujeitos adolescentes lidarem com seus corpos. Esse discurso tem como agente o objeto $a$, por isso esta parte foi intitulada Adolescência: como (a)bordar?

A segunda parte do texto dedica-se ao exame da relação entre o Corpo próprio e o corpo do Outro. Para a psicanálise, é na relação com o Outro da linguagem que a criança pode vir a construir uma imagem do seu corpo, a partir e na confluência da imagem do outro que é um arauto do Outro. O outro é o semelhante, outro ser vivo, e é através dele que a criança pode fazer sua entrada na linguagem.

Entre o sujeito e o Outro todo, o campo pulsional e libidinal pode se formalizar na tentativa de criar condições de laços entre os falantes. Nunca haverá uma reciprocidade completa entre o sujeito e o Outro, dado o risco de submissão do sujeito

$\overline{1}$ Neologismo usado por Lacan e definido por ele como “esse fora que não é um não-dentro" (Lacan, 2007a). O termo é sustentado pela lógica da geometria topológica, na qual o paradoxo espacial é aceito. 
aos desígnios deste último. $\mathrm{O}$ texto argumenta que o sintoma, para a psicanálise, seria uma maneira dos sujeitos adolescentes se questionarem sobre sua relação com o Outro, na busca de encontrar formas de lidar com seus funcionamentos psíquicos, que está articulada com a maneira como subjetivam seus corpos.

A teoria dos discursos trabalhada por Jacques Lacan é retomada nesta parte para contrapor certa patologização da adolescência que insiste em se fazer presente na confluência entre o discurso do capitalismo e do discurso mestre. No primeiro, a tentativa de fazer relação direta com os objetos desconsidera que o sujeito não é uma substância, mas sim um efeito da linguagem. No segundo, há a tentativa de patologizar através de diagnósticos que se apoiam na observação de comportamentos em descontinuidade com a fala dos sujeitos. Os diagnósticos tentam dar substância ao que há de insubstancial no corpo do ser falante, atravessado pela libido e pelas pulsões. Alguns recortes de casos clínicos, nesta parte, tentam dar tratamento a essas questões.

\section{Adolescência: Como $(A)$ Bordar?}

Tem sido frequente, na contemporaneidade, diferentes discursos fabricarem pacotes classificatórios em função de conjunturas e de problemas que supostamente se relacionam com as etapas da vida. Embora a psicanálise se coloque na contramão disso, procedendo de um a um, "ela não se excetua na fabricação de categorias, como nas estruturas clínicas: neurose, psicose, perversão; mas há também as mulheres e as mães, muito na moda, e igualmente as crianças e adolescentes" (Soler, 2017, p. 35).

A autora considera que, de todas, essas duas últimas "estão mais ajustadas ao que Freud revelou quando descobriu o inconsciente" (Soler, 2017, p. 35). A questão da infância e do que resta do infantil na estrutura do sujeito está posta desde Freud e é partilhada por diversos autores até hoje. Mas, e quanto ao "sujeito adolescente"? O que podemos dizer sobre a sua relação com o inconsciente? E ainda: como o sujeito adolescente lida com a diferença sexual?

Entendemos que o termo "sujeito adolescente" (Alberti, 2009), embora não tenha sido utilizado pelos cânones, está em consonância com o ensino de Freud e de Lacan sobre o inconsciente estruturado como uma linguagem. O sujeito tomado em sua relação com o significante não designa "o substrato vivo de que precisa o fenômeno subjetivo, nem qualquer espécie de substância" (Lacan, 2008a, p. 126), mas sua constituição diz respeito à divisão própria da linguagem entre o dito e o dizer. O sujeito é, portanto, efeito, e não substância. Na psicanálise, o sujeito não se confunde com a pessoa nem com o eu, e "deve ser distinguido tanto do indivíduo biológico quanto de qualquer evolução psicológica classificável” (Lacan, 1998b, p. 890).

Enquanto o indivíduo adolescente (púbere) indica uma pessoa que se encontra em uma determinada faixa etária, cujo limite cronológico varia muito, conforme o órgão ou documento legal, e na qual se constata transformações biológicas, o sujeito adolescente indica o efeito, a resposta aos impasses da vida humana, que se dá a ver pelas formações do inconsciente. Embora Freud (1905/1996d) tenha sempre utilizado o termo puberdade e isso mereça uma atualização, faz-se necessário que estejamos advertidos de que as construções freudianas sobre a questão transcendem a dimensão estritamente orgânica, haja vista o conceito de pulsão, que subverte a divisão estanque entre o psíquico e o somático.

Feita essa ressalva, encontramos em Freud algumas pistas sobre o que poderíamos considerar como especificidade do tempo lógico chamado adolescência. Uma das mais emblemáticas é a ideia de que nesse tempo "consuma-se uma das realizações psíquicas mais significativas, porém também mais dolorosas, (...) o desligamento da autoridade dos pais" (Freud, 1905/1996d, p. 214). Isso quer dizer que o sujeito é convocado a dar sua resposta, em nome próprio, ao fato de estrutura, escrito por Lacan pela fórmula $S(A)$, significante da falta no Outro, ou seja, ao fato que indica que o Outro é inconsistente, é faltante tal qual o sujeito.

No que concerne a essa tarefa de "desligamento da autoridade parental" (Gerbase, 2010, p 26), é importante ressaltar que o outro parental é tão somente um arauto do Outro, este sim traumático por estrutura. Segundo Gerbase (2015, p. 54), as formações do inconsciente são fatos de linguagem, formações do significante, e, por isso, "fazer condensação e deslocamento não depende da família, mas da fala, ainda que da fala de papai e mamãe". Por conseguinte, tratando-se da estrutura de linguagem, para se examinar a questão da alteridade na psicanálise, é fundamental o par seja sujeito-Outro.

Para tanto, as operações de causação do sujeito - alienação e separação -, formuladas por Lacan, ajudam a pensar esse movimento. Enquanto a alienação diz respeito a uma escolha forçada de entrada na linguagem, que implica a divisão do sujeito (- \$ - ) - "uma vida decepada" (Lacan, 2008a, p. 207) -, a separação diz respeito a um retorno da alienação. Isso ocorre porque a relação entre o sujeito e o Outro é circular e não recíproca, pois não há simetria, justaposição ou correlação "do sujeito chamado ao Outro, ao sujeito pelo que ele viu a si mesmo aparecer no campo do Outro, do Outro que lá retorna" (Lacan, 2008a, p. 196). Assim, é quando se depara com a falta do Outro, com a sua inconsistência, que o sujeito responde com sua própria falta, ou seja, com aquilo de mais radical na sua constituição, a divisão.

Aquilo que Freud chamou de "desligamento" já se coloca para a criança e podemos pensar nos tempos de efetuação da estrutura como marcos desse encontro do real. No entanto, o que se passa na infância, enquanto instante de ver, resta como traço a ser elaborado num sódepois, como apresentado na tese freudiana sobre a sexualidade infantil: "nenhuma experiência 
sexual produz qualquer efeito enquanto o sujeito ignora toda e qualquer sensação sexual - quer dizer, em geral antes do início da puberdade" (Freud, 1895/1996c, p. 385).

Dito isso, parece que a especificidade da adolescência tem alguma relação com o saber, pois, após o "instante de ver", há uma convocação à travessia $n a$ fantasia $(\$ \diamond$ a): se antes a criança ocupava o lugar de objeto para um sujeito, agora ela é chamada a assumir o lugar de sujeito em relação (conjunção, disjunção) a seus próprios objetos. Dessa maneira, sem planejamento prévio, sem um manual que possa prepará-lo, o sujeito é lançado no "jogo de escolhas" que é a vida, nas palavras de um jovem analisante. O sujeito é jogado no "tempo de compreender" (Lacan, 1998c), tempo de construir um lugar para si, conforme Costa (2014). Tempo em que "hipóteses são construídas (...) sobre o que se ignora de si. Entretanto, não se pode dar garantias sobre as pressuposições, pois não existe um significante que consiga fixar o sujeito em seu ser" (Costa, 2014, p. 510).

Freud (1895/1996c, p. 411) faz uma interessante analogia: "cada indivíduo adolescente porta traços de memória que só podem ser compreendidos com a manifestação de suas próprias sensações sexuais; todo adolescente, portanto, traz dentro de si o germe da histeria". O que seria o germe da histeria? Aproveitando o rastro deixado por Freud, poderíamos propor, utilizando a teoria dos discursos de Lacan (1992), que a adolescência, enquanto tempo lógico emblemático de encontro com a falta no Outro, teria como paradigma o discurso da histérica, a $\square \$ / S_{1} \square \mathrm{S}_{2}$, no qual o sujeito dividido (\$) está em posição de agente interpelando o outro, enquanto significante mestre (), para produzir um saber (), deixando um resíduo (a) na operação.

Qual o saber que se pretende produzir nesse discurso? Lacan (1992, p. 98) diz que o discurso da histérica tem o mérito de "manter na instituição discursiva a pergunta sobre o que vem a ser a relação sexual, ou seja, de como um sujeito pode sustentá-la ou, melhor dizendo, não pode sustentá-la". Não pode sustentá-la, porque é da ordem do impossível fazer, de dois, um; e o objeto $a$, aparecendo no lugar da verdade nesse discurso, atesta essa impossibilidade, tanto pela sua dimensão de perda - "é isto que designa a letra que lê como sendo objeto $a$ " (Lacan, 1992, p. 13) - quanto pela característica da verdade enquanto um lugar - "nunca se pode dizê-la a não ser pela metade" (Lacan, 1992, p. 36).

Tomar esse como o discurso paradigmático do sujeito adolescente favorece, ainda, a ética do cuidado, uma vez que supor que, no grito, na rebeldia, na escarificação, no sintoma, há um sujeito, torna possível manejar tudo isso como um apelo. É nesse viés que a psicanálise pode ser útil no percurso de elaboração dessas turbulências, uma vez que se opera pelo discurso chamado do analista, o qual, assumindo a função de semblante de objeto (a), possibilita que o sujeito (\$) compareça e produza seus significantes () em associação livre, mostrando que não há um saber () que responda pela verdade, já que ela é não-toda.

Esse discurso favorece que o sentido deslize, operando justamente nas cristalizações embutidas em todos os "eu sou" para promover giros. $\mathrm{O}$ analista, assim, cria condições para que o sujeito tenha desejo de saber. Abre, com isso, um campo de invenção para que ele consiga tanto fazer borda nas experiências mais mortíferas que o fazem se sentir à deriva no vazio de sentido quanto, caso seja possível, bordar, com seus significantes, uma nova trama dos fios deixados pelo romance familiar. Este se mostra, passo a passo, insuficiente para dar conta dos enigmas do amor e da morte e, também, de uma questão incisiva, que é a de como (a)bordar o corpo do Outro. Desenvolveremos esse último ponto a seguir.

\section{O Corpo Próprio e Corpo do Outro}

Não há como não se deparar com a questão das transformações pubertárias em um determinado momento da vida. No que tange à adolescência, parece haver um ponto de disjunção entre esta e a puberdade, denunciado pela própria existência lógica da temporalidade inconsciente. Essa não conformação puberdade-adolescência, inclusive, fica evidente nas discussões contemporâneas sobre o que Birman (2011, p. 2) chama de "alongamento da adolescência", a qual "começa hoje bem mais cedo do que outrora e que se prolonga também bastante, no campo que se denominava antigamente de idade adulta". Talvez possamos questionar se há mesmo um alongamento - o que supõe que algo começou em um ponto específico e se estendeu - ou se o sujeito pode passar pela puberdade, mas só se deparar com a adolescência enquanto tempo lógico de convocações em um só-depois das transformações pubertárias.

O corpo objeto da medicina não levanta suspeitas, já que esse discurso faz equivaler corpo e organismo, e todo furo no saber é pretensamente tamponado a cada descoberta das tecnologias e da ciência. Todavia essa suspeita se impõe nesse discurso quando, no corpo, não se encontra evidência, por sua vez entendida como prova etiológica pela fisiologia ou pela anatomia. Podemos dizer que foi nesse ponto que a psicanálise começou e de onde partiu Freud, neurologista, que, sob influência da escola francesa, especialmente pela experiência com Charcot, pôde questionar sobre o que faz com que alguém apresente sintomas motores sem que isso seja efeito de disfunção ou lesão nas células nervosas: "nas suas paralisias e em outras manifestações, a histeria se comporta como se a anatomia não existisse, ou como se não tivesse conhecimento desta" (Freud, 1893/1996b, p. 212). Assim, o sintoma histérico escancara esse "mistério do corpo falante" (Lacan, 2008b, p. 140) e Freud foi suficientemente sensível para permitir que o dado clínico se sobrepujasse à teoria localizacionista.

No texto Tratamento psíquico ou anímico, Freud (1890/1996a, p. 272) discute a divisão entre o somático e o psíquico, fazendo uma crítica à medicina de sua época, que insistia em "representar o anímico como determinado pelo físico e 
dependente deste", recuando ante a possibilidade de autonomia do registro psíquico "como se com isso fossem abandonar o terreno da cientificidade". O corpo humano, dessa maneira, não respeita o mapa anatômico, não é um dado de natureza, mas se fabrica com o discurso e isso o define como "corpo sensível a um dizer" (Lacan, 2007b, p. 18) e o separa radicalmente do organismo puramente animal no qual "há instinto, ou seja, o saber que sua sobrevivência implica" (Lacan, 2003, p. 510).

Pela intrusão da linguagem, que marca definitivamente a carne do ser falante, se transforma radicalmente a relação do sujeito com seu corpo, posto que o sujeito não é um corpo, mas crê que o tem. "Na realidade ele não o tem, mas seu corpo é sua única consistência, consistência mental, é claro, pois seu corpo sai fora a todo instante; o corpo decerto não se evapora e nesse sentido ele é consistente" (Lacan, 2007b, p. 64).

Nessa mesma aula, Lacan define consistência pelo que mantém junto, e é por isso que ela é simbolizada pela superfície. "Só temos ideia de consistência pelo que se constitui saco. Mesmo o corpo nós o sentimos como pele retendo em seu saco um monte de órgãos" (Lacan, 2007b, p. 63). Desse modo, aquilo que o sujeito acredita possuir, o que sente como corpo próprio, é similar ao eu em sua consistência e, como demonstra Freud, ambos são "entidade de superfície", daí vem a ideia de que tanto o corpo quanto o eu são instâncias que conferem alguma ideia de unificação.

Segundo Freud (1923/1996h, p. 39), "o eu é, primeiro e acima de tudo, um eu corporal, não é uma entidade de superfície, mas é, o próprio eu, a projeção de uma superfície". Na nota de rodapé do mesmo texto, ele afirma que o eu pode ser encarado como uma projeção mental da superfície do corpo. Essa tese freudiana está alinhada ao complexo ótico que Lacan chama de estádio do espelho, o qual foi definido por ele como "a transformação produzida no sujeito quando ele assume uma imagem" (Lacan, 1998d, p. 97). A fundação do eu, via imagem especular, confere a assunção imaginária de um corpo. E essa articulação freudo-lacaniana está na base do argumento da "adolescência como só-depois do estádio do espelho", que o psicanalista francês Jean-Jacques Rassial propõe.

O estádio do espelho é o momento - lógico, tanto quanto cronológico - em que o sujeito constitui num eu este objeto separado da mãe, dependente, defeituoso, representado por um corpo, fechado pela pele e capaz de um mínimo de autonomia. Momento, pois, de fechamento ilusório (mas decisivo) do sujeito num corpo e ao mesmo tempo de abertura para o mundo objetal e as dimensões do outro e do Outro. (Rassial, 1999, p. 45)

Isso seria o que acontece na infância: "um fechamento decisivo num corpo". No entanto, quando Lacan fala de "assumir uma imagem", é importante que se diga que uma imagem não é encerrada no imaginário, ela comporta uma cota de real que resta inapreensível. Assim, podemos argumentar que o estádio do espelho não garante unidade corporal nem tampouco do eu. Todavia, evidentemente, há algo dessa ordem, uma sedimentação feita via sentido que constrói certa borda de fato, mas o contorno segue poroso, borrado. E a barreira entre o eu e o Outro chega à adolescência por fazer.

A questão é que, conforme Rassial (1999), a estruturação da imagem do corpo, que já aconteceu, é agora posta à prova, uma vez que a puberdade fisiológica perturba essa imagem construída na infância. Diante dessa colocação, cabe perguntar: seriam a aparição dos caracteres secundários e a ebulição hormonal que desarrumariam o que ali já estava pronto? Ou o próprio complexo eu-corporal é parcial e fragmentado mesmo desde a infância?

A relação do ser humano com seu corpo, apesar de este ser absolutamente capturado pela sua imagem, é marcada pela estranheza e pelo mal-estar (Rinaldi, 2011). O corpo dito próprio é, na verdade, um estranho. Uma série de experiências que se escuta na clínica atesta isso, como quando uma analisante chama de "despersonalização" se olhar no espelho e não se ver, gerando uma série de questões sobre sua identidade; ou quando alguém em franca tristeza que diz sobreviver apesar desse "corpão" de mulher que sente como fardo desde a puberdade. A própria experiência invasiva da alucinação na psicose, a conversão histérica, a cisalha do pensamento obsessivo, o fenômeno psicossomático, a enurese noturna, a encoprese nas crianças, a síndrome do membro fantasma em amputados, a anorexia etc., são diversos os exemplos que indicam que a relação do humano com seu corpo está longe de ser natural. "Sua consistência, na verdade, só pode ser mental, em que a sexualidade, ao se dizer, mente e deixa um resto. Por isso o corpo escapa a todo instante e só pode ser tocado como sintoma" (Rinaldi, 2011, p. 442).

O sintoma, modo de acesso a alguma verdade do sujeito, toca o corpo a qualquer tempo da vida. Para Rassial (1999, p. 19), no entanto, pelas modificações que excedem o corpo imaginário, "a puberdade pode ser vivida por alguns adolescentes como uma doença". Pensamos que não é necessário à psicanálise sustentar essa ideia ou, do contrário, corremos o risco de cair na patologização da experiência adolescente. Ao contrário de "doença", o conceito de "sintoma" indica uma saída singular, o modo que cada um encontrou de se sustentar e que tem um sentido conforme descoberto por Freud, e uma relação com a realidade sexual do inconsciente (Lacan, 1998e).

Sabemos que nem tudo de que o sujeito se queixa é um sintoma, nem mesmo todos os problemas dos quais falam os adolescentes são sintomas (Soler, 2017). Para Soler (2017), a tese fundamental é que todo sintoma clínico é um sintoma sexual, e, por sexual, podemos dizer que é o que tangencia as relações entre o sujeito e o Outro. Alguns autores vêm 
trabalhando nessa direção e apontam, por exemplo, a anorexia como "a recusa do sujeito a satisfazer o Outro da demanda" (Fuks \& Pollo, 2010), a escarificação "como experiência que vincula, pela corporeidade, o sujeito ao Outro" (Oliveira, 2016), e as tatuagens e piercings como "marcas que buscam fazer borda, são recortes que têm a ver com a erotização e sua necessidade de suporte no Outro" (Costa, 2003 citado por Moreira, Teixeira, \& Nicolau, 2010, p.588).

Assim, mais do que um movimento a posteriori de "se reapropriar de uma imagem do corpo" - que segue pendente durante a vida - nesse sódepois próprio da adolescência, a especificidade maior é que "há um desmoronamento da consistência parental imaginária do Outro" (Rassial, 1999, p.49). Isso ocorre pelo próprio movimento pendular alienaçãoseparação, no qual, no fechamento do circuito, há um recobrimento das duas faltas. O que é revelado a partir da extração do objeto é que a divisão do sujeito também está para o Outro, e a este também falta um significante (Lacan, 2008a). É o encontro faltoso sobre o qual Lacan (2003) se refere com frequência e que pode ser tomado como um encontro bemsucedido com a inconsistência do Outro, $S(\AA)$.

O encontro com o real, entendido em psicanálise como o irredutível à linguagem, se dá em todos os momentos da vida do sujeito, no entanto, a puberdade aparece como um momento paradigmático desse encontro. Nele, o sujeito adolescente precisará criar uma solução própria para lidar com o não saber fazer com essa dimensão real que emerge a partir do corpo. (Guerra, Cunha, Costa, \& Silva, 2014, p. 171)

Desse modo, "a adolescência é a idade do encontro com o corpo do Outro" (Soler, 2017, p. 36), e desenvolveremos essa frase nas próximas páginas. Essa formulação não quer dizer o encontro com outro organismo, indivíduo ou aparato genital. O corpo do outro, assim escrito com minúscula, é aquele do qual o sujeito supõe gozar e isto é a promessa da puberdade. Conforme Backes (2004), na interdição da sexualidade da criança também está inscrito um juramento de que não se pode gozar do corpo dos pais, mas que, em outro tempo, será permitido gozar de outro corpo, ou melhor, que será possível fazê-lo. Essa promessa se liga a ideia de um primado da genitalidade com o advento da puberdade.

Conforme Rassial (1999, p.18), embora o corpo da criança também tenha sofrido transformações importantes no curso do seu desenvolvimento, na adolescência, "este corpo muda de estatuto essencialmente porque a genitalidade ocupa uma posição dominante para o sujeito". O autor coloca ênfase no fato de que, com a puberdade, haveria a assunção de um "corpo genitalmente maduro", e essa ideia nos parece um pouco problemática, merecendo algumas ponderações.

Para começar, a ideia da assunção da genitalidade não é de Rassial (1999), mas de Freud, e aparece nos Três ensaios sobre a teoria da sexualidade, em que ele apresenta "as fases de desenvolvimento da organização sexual". Nesse esquema, a vida sexual infantil (essencialmente autoerótica e formada por pulsões parciais, independentes entre si) segue um percurso que culmina com a puberdade, em um aparelho que atingiu o seu propósito: "a pulsão sexual coloca-se agora a serviço da função reprodutora [grifo nosso]; torna-se altruísta, por assim dizer” (Freud, 1905/1996d, p. 196).

O desfecho do desenvolvimento constitui a chamada vida sexual normal do adulto, na qual a obtenção de prazer fica a serviço da função reprodutora, e as pulsões parciais, sob o primado de uma única zona erógena, formam uma organização sólida para consecução do alvo sexual num objeto sexual alheio. (Freud, 1905/1996d, p. 186)

A concepção de Freud, nesse momento, é a de uma evolução que iria do autoerotismo ao ato copulatório, passível de acontecer porque as zonas genitais “assumiram seu papel preponderante”. Essa tese é comentada por Lacan no Seminário XI:

A descrição dos estágios, formadores da libido, não deve ser referida a uma pseudomaturação natural, que permanece sempre opaca. Os estágios se organizam em torno da angústia de castração. O fato copulatório da introdução da sexualidade é traumatizante - aí está um fisgamento de vulto - e tem uma função organizadora para o desenvolvimento. A angústia de castração é como um fio que perfura todas as etapas do desenvolvimento. Ela orienta as relações que são anteriores à sua aparição propriamente dita - desmame, disciplina anal etc. Ela cristaliza cada um desses momentos numa dialética que tem por centro um mau encontro. Se os estágios são consistentes, é em função de seu registro possível em termos de mau encontro. (Lacan, 2008a, p. 68)

É preciso atualizar o que Lacan aí chama de "angústia de castração" para $S(A)$, de modo que é o "mau encontro" o cerne do problema. Seguindo essa indicação de Lacan, podemos voltar, então, a Freud e notar que esse descompasso se dá desde o seguinte postulado: "uma só libido" (Freud, 1905/1996d, p. 207), independentemente dos "caracteres sexuais físicos", "caracteres sexuais mentais" ou "tipo de escolha de objeto". Atualizaríamos o postulado de Freud, para um só significante, o falo, ou há-Um.

2 Freud (920/1996f, p. 182) faz essa diferenciação no texto A Psicogênese do Caso de Homossexualismo de uma Mulher e pondera que "essas características, até certo ponto, variam independentemente uma da outra e em indivíduos diferentes são encontradas em permutações múltiplas". 
Sendo assim, a questão está posta: se há-Um, como ( $a$ bordar o corpo do Outro? Na verdade, a pergunta que Lacan faz é: "de onde parte o que é capaz de responder pelo gozo do corpo do Outro?". A resposta dada por ele é que não é do amor, mas do "amuro":

O amuro é o que aparece em signos bizarros no corpo. São esses caracteres sexuais que vêm do além, desse local que temos acreditado podermos ocular no microscópio sob a forma de gérmen (...) é de lá que vem o mais, o em-corpo, o A inda. É, portanto, falso dizer que há separação do soma e do gérmen, pois, por alojar esse gérmen, o corpo leva seus traços. Há traços no amuro. (Lacan, 2008b, p. 12)

A maturação biológica que torna possíveis a função reprodutora e o coito, passível de ocorrer na adolescência, gera esse engodo, esse "boato da puberdade e da pulsão genital, porque, de fato, os caracteres sexuais secundários fazem do gozo um gozo sexuado, mas o gozo do ser é o gozo do corpo como assexuado" (Gerbase, 2007, p. 78). É assexuado, segundo Gerbase (2007), por ser marcado pela impossibilidade de estabelecer o Um da relação sexual.

Assim, o encontro com o Outro não é pacífico, pois, muito além do ato sexual (mas também nele), trata-se de um "mau encontro", até mesmo quando há o orgasmo, porque a linguagem coloca o humano em uma posição outra que não a da completa submissão às necessidades. Inclusive nos casos em que supomos haver uma complementaridade, como no caso do par masoquismo-sadismo, e Lacan (1999) exemplifica bem esse desencontro com um chiste em que o masoquista diz ao sádico: "me machuca", ao que este responde, "não".

Quem está mais fadado a se entender do que o masoquista e o sádico? Sim, mas, como estão vendo por essa história, desde que não falem um com o outro. Não é por maldade que o sádico responde não. Ele responde em função de sua condição sádica. $\mathrm{E}$ a partir do momento em que se fala, ele é obrigado a responder no nível da fala (Lacan, 1999, p. 72)

Um jovem, em análise, dizia o seguinte: “já perguntaram se eu me mutilo. Uma amiga diz que pessoas depressivas fazem isso para castigar elas mesmas. Quando você se corta, você não sente a dor. Sua cabeça fica em outro lugar. Você não sente o sangue escorrendo, o molhado do sangue (...) você não sente nada". "Você não sente nada?", questiona a analista, e ele diz "Sou uma pessoa que não sente. Acho que nunca senti nada forte por ninguém". O que há de interessante nesse fragmento é como o verbo sentir desliza de "experimentar uma sensação", uma dor no corpo próprio, para o sentido de "nutrir um sentimento" (le senti-ment, ou o sentido mente, como diria Lacan) por outrem. Esse deslizamento ilustra bem o corpo de que se trata e mostra como há um imbricamento entre o dito corpo próprio (esse nosso corpo estranho) e o corpo do Outro.

A dimensão da linguagem tira dos humanos a possibilidade de satisfação total de suas necessidades e, na verdade, nem podemos falar nesses termos, já que "desde a origem, a necessidade tem sua motivação no plano do desejo, isto é, de alguma coisa que se destina, no homem, a ter uma certa relação com o significante" (Lacan, 1999, p. 227). Daí a postulação de que, com o "despertar da primavera", forma metafórica de se referir à adolescência, é sempre da ordem de um mau encontro de que se trata, já que todas as promessas de felicidade futura, que justificaram a renúncia edípica no período de latência, não se realizam (Backes, 2004). A demanda pela completude, por atingir a comunhão dos corpos, é derrisória, porque "só se pode gozar de uma parte do corpo do Outro, pela simples razão de que jamais se viu um corpo enrolar-se completamente, até incluí-lo e fagocitá-lo, em torno do corpo do Outro" (Lacan, 2008b, p. 29).

Por essa razão, em psicanálise, ao invés de "corpo do outro", com minúscula, dizemos "corpo do Outro" já que essa proposição, diferente da anterior, se sustenta na impossibilidade de comunhão, de fazer de dois, um. Não é possível gozar do corpo do Outro porque ao sujeito só dado acesso parcial a esse corpo, via objeto $a$, como vemos no matema da fantasia: $\$ \diamond a$. Assim, "gozar tem essa propriedade fundamental de ser em suma o corpo de um que goza de uma parte do corpo do Outro" (Lacan, 2008b, p. 30).

Dessa maneira, o "corpo de um" (esse que chamamos indevidamente de próprio, já que nada é mais estranho, êxtimo) experimenta as transformações pubertárias e o trabalho psíquico de subjetivação dessas mudanças, que, embora sejam significativas, não revelam precisamente um corpo inteiramente novo, mas escancaram a natureza fragmentada do corpo do humano pela própria intrusão da linguagem.

Essa natureza fragmentada pode ser ilustrada com a seguinte vinheta clínica. Alguém, cujo sintoma é comer nada como Lacan nomeia a anorexia - segue em franca tristeza e diz sobreviver, apesar do corpo próprio. Com o percurso de sua análise, pôde dizer que esse corpo de mulher, ela o sente como fardo desde o início da puberdade, quando ouve de outrem: "você tem um corpão". Esse significante faz uma marca e, pela via do que equivoca (corpo feminino desejável x corpo gordo), mostra bem qual a estrutura do corpo humano: não o corpo mítico esférico, mas o corpo topológico, tórico, furado. Assim, nesse exemplo, interessam menos as transformações pubertárias e mais a contingência do ouvir, o que aponta para um dos orifícios do corpo furado e a intromissão do objeto $a$, seja pela voz, seja pelo olhar. 
Portanto, o corpo faz barulho, mesmo nos adultos que já passaram pelos percalços da puberdade. A angústia é prova disso: o afeto que não engana, sinal do real que comumente aparece - na tentativa de circunscrever o que não tem palavras - como um desconforto no corpo, um aperto, um sufocamento. E o adolescente, tal qual a criança, está mal preparado para lidar com isso, o que não implica que chegar à idade adulta assegure as rédeas do saber sobre o corpo, já que a passagem dos anos por si não garante "alcançar um sentido pleno para a estranheza que o invade pelos poros ou pelo dissonante olhar alheio" (Matheus, 2008, p. 623).

É pela via desse pedaço do Outro que o corpo dito próprio ganha consistência: “o corpo ganha seu peso pela via do olhar" (Lacan, 1998e, p. 3). Por isso, só podemos falar do corpo na adolescência (e em qualquer outro tempo lógico, aliás) se recorrermos a essa engrenagem que implica os três termos: sujeito, Outro e objeto $a$. Engrenagem essa na qual, pelo que sabemos, o objeto é a única interseção entre o sujeito e o Outro, todavia uma interseção impossível de instaurar a relação sexual. Dessa maneira, podemos dizer que a real convocação aos sujeitos é esta: o dever ético de inventar um modo singular de estar no mundo e de fazer laço social.

\section{Considerações Finais}

Se, para Freud (1895/1996c, p. 385), "nenhuma experiência sexual produz qualquer efeito enquanto o sujeito ignora toda e qualquer sensação sexual - quer dizer, em geral antes do início da puberdade", então cabe questionar o que se passa aí nesse tempo em que ocorre o que ele chama de transformações da puberdade. Na trilha de Freud, Parada (2017) diz que a novidade que se instaura no tempo lógico da adolescência é a de trazer de volta, mas de maneira diferente, as questões da infância, como a identidade sexual e a procriação, que terão de ser tratadas novamente, sob uma nova luz. Além da questão do encontro com o corpo do Outro, perguntas que retornam sobre o sujeito, como "sou um menino ou sou uma menina?" e “como ser um menino? Como ser uma menina?", são atualizadas, uma vez que a resposta imaginária da infância não é mais suficiente (Parada, 2017).

Essas questões e diversas outras encontram no corpo, tomado em todas as suas dimensões, um emaranhado de enigmas que, de algum modo, sempre se apresentaram aos púberes ao longo da história da humanidade. Todavia não podemos perder de vista as especificidades do nosso tempo, pois, como afirma Birman (2006), o corpo é o registro mais eminente no qual se enuncia o mal-estar na contemporaneidade. A clínica com sujeitos chamados adolescentes denuncia esse malestar na civilização, dando a ver com maior nitidez as formas contemporâneas de sofrimento e subjetivação. Podemos dizer que a juventude fornece elementos importantes para se pensar a subjetividade na contemporaneidade, e questões como a escarificação e a anorexia, que tangenciamos neste artigo, escancaram o corpo em sua dimensão mais além do organismo.

\section{Referências}

Alberti, S. (2009). Esse sujeito adolescente. Rio de Janeiro: Rios Ambiciosos/Contracapa

Almeida, P. (2019). Trançar e tecer a feminilidade na adolescência: A construção do caso clínico em psicanálise. Dissertação de Mestrado, Instituto de Psicologia, Universidade Federal da Bahia, Salvador.

Backes, C (2004). A reconstituição do espelho. In A. Costa, C. Backes, V. Rilho, \& L. F. L. Oliveira (Orgs.), Adolescência e experiências de borda (pp. 29-41). Porto Alegre: Editora da UFRGS.

Birman, J. (2006). Arquivos do mal-estar e da resistência. Rio de Janeiro: Civilização Brasileira.

Birman, J. (2011). Tatuando o desamparo. In: M. Cardoso (Org.), Adolescentes. (2a Ed., pp. 25-43). São Paulo: Escuta.

Costa, A. (2014). Os tempos da transmissão segundo a lógica de Lacan. Estilos da Clínica, 19(3), 499-514.

Freud, S. (1996a). Tratamento psíquico ou anímico. In J. Strachey (Ed.), Edição Standard Brasileira das Psicológicas Completas de Sigmund Freud (Vol. 1). Rio de Janeiro: Imago. (Originalmente publicado em 1890)

Freud, S. (1996b). Algumas considerações para um estudo comparativo das paralisias motoras orgânicas e histéricas. In J. Strachey (Ed.), Edição Standard Brasileira das Psicológicas Completas de Sigmund Freud (Vol. 1). Rio de Janeiro: Imago. (Originalmente publicado em 1893) 
Freud, S. (1996c). Projeto para uma psicologia científica. In J. Strachey (Ed.), Edição Standard Brasileira das Psicológicas Completas de Sigmund Freud (Vol. 1). Rio de Janeiro: Imago. (Originalmente publicado em 1895)

Freud, S. (1996d). Três ensaios sobre a teoria da sexualidade. In J. Strachey (Ed.), Edição Standard Brasileira das Obras Psicológicas Completas de Sigmund Freud (Vol. 7). Rio de Janeiro: Imago. (Originalmente publicado em 1905)

Freud, S. (1996e). Recomendações aos médicos que exercem a psicanálise. In J. Strachey (Ed.), Edição Standard Brasileira das Psicológicas Completas de Sigmund Freud (Vol. 12). Rio de Janeiro: Imago. (Originalmente publicado em 1912)

Freud, S. (1996f). A psicogênese do caso de homossexualismo de uma mulher. In J. Strachey (Ed.), Edição Standard Brasileira das Psicológicas Completas de Sigmund Freud (Vol. 18). Rio de Janeiro: Imago. (Originalmente publicado em 1920)

Freud, S. (1996g). Psicologia de grupo e a análise do ego. In J. Strachey (Ed.), Edição Standard Brasileira das Obras Psicológicas Completas de Sigmund Freud (Vol. 18). Rio de Janeiro: Imago. (Originalmente publicado em 1921)

Freud, S. (1996h). O ego e o id. In J. Strachey (Ed.), Edição Standard Brasileira das Obras Psicológicas Completas de Sigmund Freud (Vol. 19). Rio de Janeiro: Imago. (Originalmente publicado em 1923)

Fuks, B. B., \& Pollo, V. (2010). Estudos psicanalíticos sobre anorexia: Quando se come "nada". Revista Latinoamericana de Psicopatologia Fundamental, 13(3), 412-424.

Gerbase, J. (2007). Os signos dos discursos. Stylus: Amor, desejo e gozo, 14, 77-92.

Gerbase, J. (2010). O poder do grande Outro. Cógito, 11, 26-28. Link

Gerbase, J. (2015). Atos de fala. Salvador: Associação Científica Campo Psicanalítico.

Guerra, A. M., Cunha, C. F., Costa, M. H., \& Silva, T. L. (2014). Risco e sinthome: A psicanálise no sistema socioeducativo. Psicologia: Teoria e Pesquisa, 30(2), 171-177.

Kyrillos Neto, F., \& Dunker, C. (2004). O ineditismo na adolescência: Originalidade, igualdade e repetição. Revista Latinoamericana de Psicopatologia Fundamental, 7(3), 56-66. Link

Lacan, J. (1992). O Seminário, livro 17: O avesso da psicanálise (1969-1970). Rio de Janeiro: Zahar.

Lacan, J. (1998a). Função e campo da fala e da linguagem em psicanálise. In J. Lacan, Escritos (pp. 238-324). Rio de Janeiro, Jorge Zahar

Lacan, J. (1998b). A ciência e a verdade. In J. Lacan, Escritos (pp. 869-892). Rio de Janeiro: Zahar.

Lacan, J. (1998c). O tempo lógico e a asserção de certeza antecipada. In J. Lacan, Escritos (pp. 197-213). Rio de Janeiro: Jorge Zahar.

Lacan, J. (1998d). O estádio do espelho como formador da função do eu. In J. Lacan, Escritos (pp. 96-103). Rio de Janeiro, Jorge Zahar.

Lacan, J. (1998e). Conferência em Genebra sobre o sintoma. Opção Lacaniana: Revista Brasileira Internacional de Psicanálise, , 23, 6-16.

Lacan, J. (1999). O Seminário, livro 5: As formações do inconsciente. Rio de Janeiro: Jorge Zahar.

Lacan, J. (2003). Prefácio a “O despertar da primavera”. In J. Lacan. Outros escritos (pp. 557-559). Rio de Janeiro: Jorge Zahar.

Lacan, J. (2007a). O Seminário, livro 22: RSI (1974-1975). Inédito. Link 
Lacan, J. (2007b). O Seminário, livro 23: O sinthoma (1975-1976). Rio de Janeiro: Zahar.

Lacan, J. (2008a). O Seminário, livro 11: Os quatro conceitos fundamentais da psicanálise. Rio de Janeiro: Jorge Zahar.

Lacan, J. (2008b). O Seminário, livro 20: Mais, ainda (1972-1973). Rio de Janeiro: Zahar.

Matheus, T. (2008). Quando a adolescência não depende da puberdade. Revista Latinoamericana de Psicopatologia Fundamental, 11(4), 616-625. Link

Moreira, A., \& Coutinho, L. (2018). Efeitos da medicalização na travessia adolescente. Revista de Psicologia, 9(1), 53-63. Link

Moreira, J. O., Teixeira, L. C., \& Nicolau, R. F. (2010). Inscrições corporais: Tatuagens, piercings e escarificações à luz da psicanálise. Revista Latinoamericana de Psicopatologia Fundamental, 13(4), 585- 598. Link

Oliveira, C. (2016). Corpo, narcisismo e identificação nas escarificações ansiolíticas entre adolescentes na atualidade. In E. Gelman (Org.), Nós do sintoma (pp.155-168). Salvador: Campo Psicanalítico.

Parada, C. (2017) La puberté, tout le monde en parle mais... Cahiers du Collège de Clinique Psychanalytique de Paris: La relation à l'autre, sa structure, ses passions (2016-2017), 18, $42-47$.

Rassial, J.-J. (1999). O adolescente e o psicanalista. Rio de Janeiro: Companhia de Freud.

Rinaldi, D. (2011). O corpo estranho. Revista Latinoamericana de Psicopatologia Fundamental, 14(3), 440-451. Link

Schoen-Ferreira, T., Aznar-Farias, M., \& Silvares, E. (2010). Adolescência através dos séculos. Psicologia: Teoria e Pesquisa, 26(2), 227-234. Link

Soler, C. (2017). L'adolescent et le réel. Cahiers du Collège de Clinique Psychanalytique de Paris: La relation à l'autre, sa structure, ses passions, 18, 35-37.

Soler, C. (2018). Rumo à identidade. São Paulo: Aller.

\section{Como citar:}

Almeida, P. S., \& Fernandes, A. H. (2020). O Sujeito Adolescente e o Corpo: Uma Leitura Psicanalítica. Revista Subjetividades, 20(Esp 2. O Contemporâneo à Luz da Psicanálise), e9311. http://doi.org/10.5020/23590777.rs.v20iEsp2.e9311

\section{Endereço para correspondência}

Pollyana Silveira de Almeida

E-mail: pollyanasalmeida@gmail.com

Andréa Hortélio Fernandes

E-mail: ahfernandes03@gmail.com 